\title{
Determination of Nitrite Plus Nitrate and Malondialdehyde in Human Plasma: Analytical Performance and the Effect of Smoking and Exercise
}

\author{
Cristina Vassalle*, Valter Lubrano, Antonio L'Abbate \\ and Aldo Clerico \\ CNR Institute of Clinical Physiology, Pisa, Italy
}

The aim of this study was to evaluate the analytical performance and clinical usefulness of spectrophotometric assays for the measurement of the plasma levels of nitrite plus nitrate (NOx), and malondialdehyde (MDA), as an index of nitric oxide release and lipid peroxidation, respectively. We studied 30 healthy sedentary volunteers, 12 endurance athletes and 12 regular heavy smokers. The lower limit of quantification for plasma NOx concentration was $1 \mu \mathrm{mol} / \mathrm{I}$, and linearity was observed from 1 to $\mathbf{4 0} \mu \mathrm{mol} / \mathrm{l}$ of NOx concentration. Variation in replicate samples within or between days was always below $\mathbf{5 \%}$. NOx levels were significantly higher in athletes compared to both control subjects and smokers $(p<0.05$ and $p<0.001$, respectively), as well as in healthy subjects compared to smokers $(p<0.05)$. The analytical limit of quantification for plasma MDA concentration was $0.03 \mu \mathrm{mol} / \mathrm{l}$, and linearity was observed from 0.03 to $20 \mu \mathrm{mol} / \mathrm{l}$ of MDA concentration. Variation in replicate samples within or between runs was $<5 \%$. Mean MDA concentration was significantly higher in smokers compared to control subjects and athletes $(p<0.001)$. A significant inverse relationship $(p<0.001)$ was observed when comparing NOx with MDA ( $r=-0.49)$ or LDL levels $(r=-0.30)$ in the total population. The assays evaluated in this study proved to be sensitive, specific and practicable, and therefore suitable for routine application in clinical chemistry laboratories and/or physiopathological studies involving human blood samples. Clin Chem Lab Med 2002; 40(8):802-809

Key words: Nitric oxide; Malondialdehyde; Endothelial function.

Abbreviations: BHT, butylated hydroxytoluene; GSH, glutathione; GSSG, oxidized glutathione; HDL, high density lipoprotein; LDL, low density lipoprotein; MDA, malondialdehyde; NO, nitric oxide; NOx, nitrite and nitrate; $\mathrm{VO}_{2 \max }$ maximal oxygen consumption.

\section{Introduction}

Nitric oxide (NO) release and oxidative reactions are of central importance in the maintenance of vascular

\footnotetext{
*E-mail of the corresponding author: cristina.vassalle@nsifc.ifc.pi.cnr.it
}

homeostasis and the progression of vascular disease. In particular, the balance between them may have important clinical implications in the processes such as atherosclerosis, where oxidant stress appears to play a pivotal role in the onset and progression of vascular lesions (1).

In these pathological settings, the NO radical molecule can inhibit lipid peroxidation by scavenging propagatory lipid peroxyl radicals, but it also behaves as a potent pro-oxidant producing peroxynitrite in the presence of superoxide anion (2). For these reasons, attention has been increasingly focused on the possibility of monitoring NO synthesis and release and the evaluation of free radical generation in tissues and biological fluids. However, direct quantitative measurement of these processes is extremely difficult and not applicable in vivo $(3,4)$.

Plasma malondialdehyde (MDA) levels, evaluated as a marker of lipid peroxidation and oxidative stress, and plasma levels of inorganic nitrites and nitrates (NOx), representing the stable and final metabolites of the NO metabolic pathway, can be measured with colorimetric assays $(3,5)$. These methods do not require specific or complex instrumentation and are not expensive or time-consuming. Consequently, the colorimetric assay for MDA and NOx may be considered the best methods to use in clinical studies aiming to evaluate the involvement of NO and oxidative stress in various pathophysiological conditions and to assess the effect of pharmacological treatments on these variables. However, no general agreement exists on their use, and the views on the specificity of these tests differ $(3,6)$.

The present study was designed to evaluate the anaIytical characteristics of these colorimetric assays. The other aim of our study was to verify the clinical reliability of these methods. In particular, we evaluated whether the MDA and NOx assays demonstrate different patterns of oxidative stress and NO bioavailability in vivo in regular smokers and endurance athletes, compared to sedentary healthy subjects.

\section{Subjects and Methods}

\section{Subjects}

We studied 30 healthy sedentary volunteers $(21$ males, 9 females, mean age $29.2 \pm 4.1$ years), 12 male endurance athletes (mean age $32.8 \pm 5$ years) and 12 smokers ( 6 males, 6 females, mean age $32.7 \pm 4.8$ years).

All subjects were non-obese and had arterial blood pressure in the normal range (Table 1); they were free from acute diseases, as determined by an interview with a clinician. Furthermore, they denied the use of any medication during the 4 weeks prior to the study. All of them had normal values for the 
Table 1 Clinical characteristics of the studied subjects.

\begin{tabular}{|c|c|c|c|}
\hline & $\begin{array}{l}\text { Sedentary volunteers } \\
(n=30)\end{array}$ & $\begin{array}{l}\text { Athletes } \\
(n=12)\end{array}$ & $\begin{array}{l}\text { Smokers } \\
(\mathrm{n}=12)\end{array}$ \\
\hline Age (years) & $29.20 \pm 4.1$ & $32.8 \pm 5$ & $32.70 \pm 4.8$ \\
\hline Body-mass index $\left(\mathrm{kg} / \mathrm{m}^{2}\right)$ & $23.12 \pm 2.3$ & $23.8 \pm 3.3$ & $24.80 \pm 3.6$ \\
\hline Systolic blood pressure $(\mathrm{mmHg})$ & $122.50 \pm 11.2$ & $123.5 \pm 6.8$ & $125.10 \pm 6.6$ \\
\hline Diastolic blood pressure $(\mathrm{mmHg})$ & $78.80 \pm 6.3$ & $76.7 \pm 4$ & $79.40 \pm 4.3$ \\
\hline Heart rate (beats/minute) & $69.10 \pm 7.3$ & $60.0 \pm 6.6$ & $68.00 \pm 5.6$ \\
\hline Total cholesterol (mmol/l) & $4.60 \pm 0.5$ & $4.9 \pm 0.6$ & $5.00 \pm 0.7$ \\
\hline HDL-cholesterol (mmol/l) & $1.30 \pm 0.3$ & $1.7 \pm 0.4^{*}$ & $1.40 \pm 0.4$ \\
\hline LDL-cholesterol (mmol/l) & $2.90 \pm 0.4$ & $3.0 \pm 0.5$ & $3.24 \pm 0.6$ \\
\hline $\mathrm{VO}_{2 \max }(\mathrm{ml} / \mathrm{kg} \min )$ & $42.20 \pm 2.8$ & $66.6 \pm 3.6^{* *}$ & $36.60 \pm 3.9$ \\
\hline
\end{tabular}

${ }^{*} \mathrm{p}<0.05$ vs. sedentary group; ${ }^{*} \mathrm{p}<0.01$ vs. sedentary group and smokers

main plasma parameters (including creatinine, urea nitrogen, glucose, uric acid, albumin, enzymes, electrolytes, and hemoglobin), normal erythrocyte and leukocyte count and normal urine analysis.

Athletes (triathletes, long distance runners and cyclists) were selected on the basis of maximal oxygen consumption $\left(\mathrm{VO}_{2 \max }\right)$ above $60 \mathrm{ml} / \mathrm{min} / \mathrm{kg}$, assessed during a graded exercise test performed on a cycle ergometer. The sedentary subjects performed no physical activity and had a $\mathrm{VO}_{2 \max }$ below $45 \mathrm{ml} / \mathrm{min} / \mathrm{kg}$ (7). Athletes were requested to avoid physical activity for $24 \mathrm{~h}$ before the day of the study.

Smokers had a smoking history of 1-2 cigarette packs/day (daily cigarette consumption: mean $22.5 \pm 8.4$ ) for at least 5 years.

All participants fasted for at least $12 \mathrm{~h}$ before the study period, were requested to adhere to a low-nitrate diet (namely, to exclude foods containing high concentration of nitrate such as cured meat, fruits and, in particular, leafy green vegetables) for $72 \mathrm{~h}$ before collection of blood samples. Women were studied on the 4th to the 7th day of their menstrual cycle.

Informed consent was obtained from each subject entering the study, and the experimental protocol was approved by the local Hospital Ethics Commitee.

\section{Blood sampling}

All subjects were examined at 9.00 am in a quiet, air-conditioned room with temperature maintained at $22-24^{\circ} \mathrm{C}$. After introduction of an indwelling cannula (Artsana SPA, Grandate, Como, Italy) into the left antecubital vein, each subject was allowed to rest in a supine position for at least $15 \mathrm{~min}$ before blood collection. Venous blood samples were collected into tubes containing dipotassium ethylenediaminetetraacetate (EDTA). Samples for MDA determination were kept on ice and centrifuged within $15 \mathrm{~min}$ after blood collection at $2500 \mathrm{~g}$ for $15 \mathrm{~min}$. Butylated hydroxytoluene (BHT) $(5 \mathrm{mmol} / \mathrm{l})$ was then added to plasma samples to prevent further oxidation.

\section{Analytical methods}

Plasma concentrations of total cholesterol, high density lipoprotein (HDL)-cholesterol and triglycerides were determined by standard laboratory methods. The concentration of low density lipoprotein (LDL)-cholesterol was calculated using the Friedewald equation, and expressed as $\mathrm{mmol} / \mathrm{l}$.

NOx assay

Plasma samples were stored at $-80^{\circ} \mathrm{C}$ for less than 2 weeks before analysis. At the time of NOx assay, plasma samples were ultrafiltered ( $30 \mathrm{kDa}$ molecular weight cut-off) and cen- trifuged at $1000 \mathrm{~g}$ for $60 \mathrm{~min}$ in order to remove hemoglobin, which is known to interfere with spectrophotometric measurements. NOx concentration in different dilutions of plasma ultrafiltrate was determined by using a reagent kit (Cayman, Ann Arbor, USA) based on the Griess reaction (8), which consists of three main steps: 1) enzymatic conversion of nitrate to nitrite by means of nitrate reductase in the presence of $5 \mathrm{mmol} / \mathrm{NADPH} ; 2)$ incubation with Griess reagent $(0.1 \% \mathrm{~N}$ (1-naphthyl)ethylenediamine dihydrochloride and $1 \%$ sulfanilamide in $2.5 \% \mathrm{H}_{3} \mathrm{PO}_{4}$ ) for $10 \mathrm{~min}$ at $25^{\circ} \mathrm{C}$ to convert nitrite into a chromophore compound; 3 ) quantitative estimation of nitrite concentration by spectrophotometric measurement of the absorbance at $540 \mathrm{~nm}$ (ETI-system, Sorin Biomedica, Vercelli, Italy). Standards for calibration curves were prepared with nitrate and taken through the full assay procedure. The results were expressed as $\mu \mathrm{mol} / \mathrm{l}$ of NOx.

\section{MDA assay}

Plasma samples were stored at $-80^{\circ} \mathrm{C}$ for less than 1 week before analysis. MDA was measured by a colorimetric assay based on the reaction among one molecule of MDA and two molecules of $\mathrm{N}$-methyl-2-phenylindole at $45^{\circ} \mathrm{C}$ to yield a stable chromophore compound. Subsequently, turbid samples were centrifuged at $15000 \mathrm{~g}$ for $10 \mathrm{~min}$ to obtain a clear supernatant with maximal absorbance at $586 \mathrm{~nm}$ (Oxis International, Inc., Portland, USA). Since MDA itself is not stable, the standards used for the construction of the calibration curves were prepared as diethylacetals and taken through the full assay procedure. The acetals were hydrolyzed during the acid incubation at $45^{\circ} \mathrm{C}$ generating MDA. The results were expressed as $\mu \mathrm{mol} / \mathrm{l}$ of MDA.

\section{Statistical analysis}

Data are expressed as mean \pm SD unless otherwise stated. The significance of differences between plasma NOx concentration and plasma MDA levels was evaluated by one-way ANOVA, and the Bonferroni correction was applied in case of multiple comparisons among the three groups of subjects. Differences were considered statistically significant at $p<0.05$. Linear regression analysis was used to assess the relationships between plasma concentrations of LDL-cholesterol, MDA and NOx.

\section{Results}

Demographic and clinical characteristics of the three studied groups are shown in Table 1. Data from ath- 
letes, sedentary subjects and smokers were comparable in terms of age and major clinical parameters. Trained individuals, in accordance with the inclusion criteria, showed an increased $\mathrm{VO}_{2 \max }$ compared to sedentary subjects (Table 1).

\section{NOx assay}

\section{Analytical performance}

The limit of quantification, defined as the concentration corresponding to the mean value of 14 determinations of the zero calibrator $+2 \mathrm{SD}$, was $1 \mu \mathrm{mol} / \mathrm{l}$. The assay was found to be linear from 1 to $40 \mu \mathrm{mol} / \mathrm{l}$ of nitrate concentration ( $r=0.99, p<0.001$ ) (Figure 1, panel A). The dilution of plasma samples (to 1:10) did not significantly modify the NOx results. Both within-run and betweenrun assay imprecision, tested by repeated measurements of 11 plasma samples with NOx concentration between 29.8 and $59.1 \mu \mathrm{mol} / \mathrm{l}$, were always below $5 \%$.

Results of the analytical recovery tests are shown in Tables 2 and 3. In order to evaluate the recovery of both analytical steps (i.e. ultrafiltration and colorimetric analysis), known amounts of NOx were added (to plasma samples to be assayed; before ultrafiltration (Table 2), as well as to ultrafiltrated plasma (Table 3). A good analytical recovery was observed for both the colorimetric analysis alone $(104.9 \pm 2.5 \%)$ and the total assay $(99.7 \pm 7.1 \%)$.

\section{Clinical results}

Plasma samples, collected from five healthy volunteers at different times throughout the day $(9 \mathrm{am}, 1 \mathrm{pm}$,

Table 2 The measurement of nitrate and nitrite. Analytical recovery excluding the ultrafiltration step.

\begin{tabular}{lllll}
\hline \multicolumn{3}{l}{ NOx concentration $(\mu \mathrm{mol} / \mathrm{l})$} & \multirow{2}{l}{ Recovery (\%) } \\
\cline { 1 - 2 } Initial & Added & Expected & Measured & \\
\hline 5.5 & 10 & 15.5 & 15.8 & 102.3 \\
5.5 & 15 & 20.5 & 21.1 & 103.0 \\
5.5 & 20 & 25.5 & 27.5 & 107.9 \\
5.5 & 25 & 30.5 & 31.2 & 102.3 \\
5.5 & 30 & 35.5 & 38.0 & 107.0 \\
5.5 & 35 & 40.5 & 42.2 & 104.3 \\
5.5 & 40 & 45.5 & 48.9 & 107.5 \\
\hline
\end{tabular}

Known NOx concentrations were added to an ultrafiltered sample with fixed known concentration.
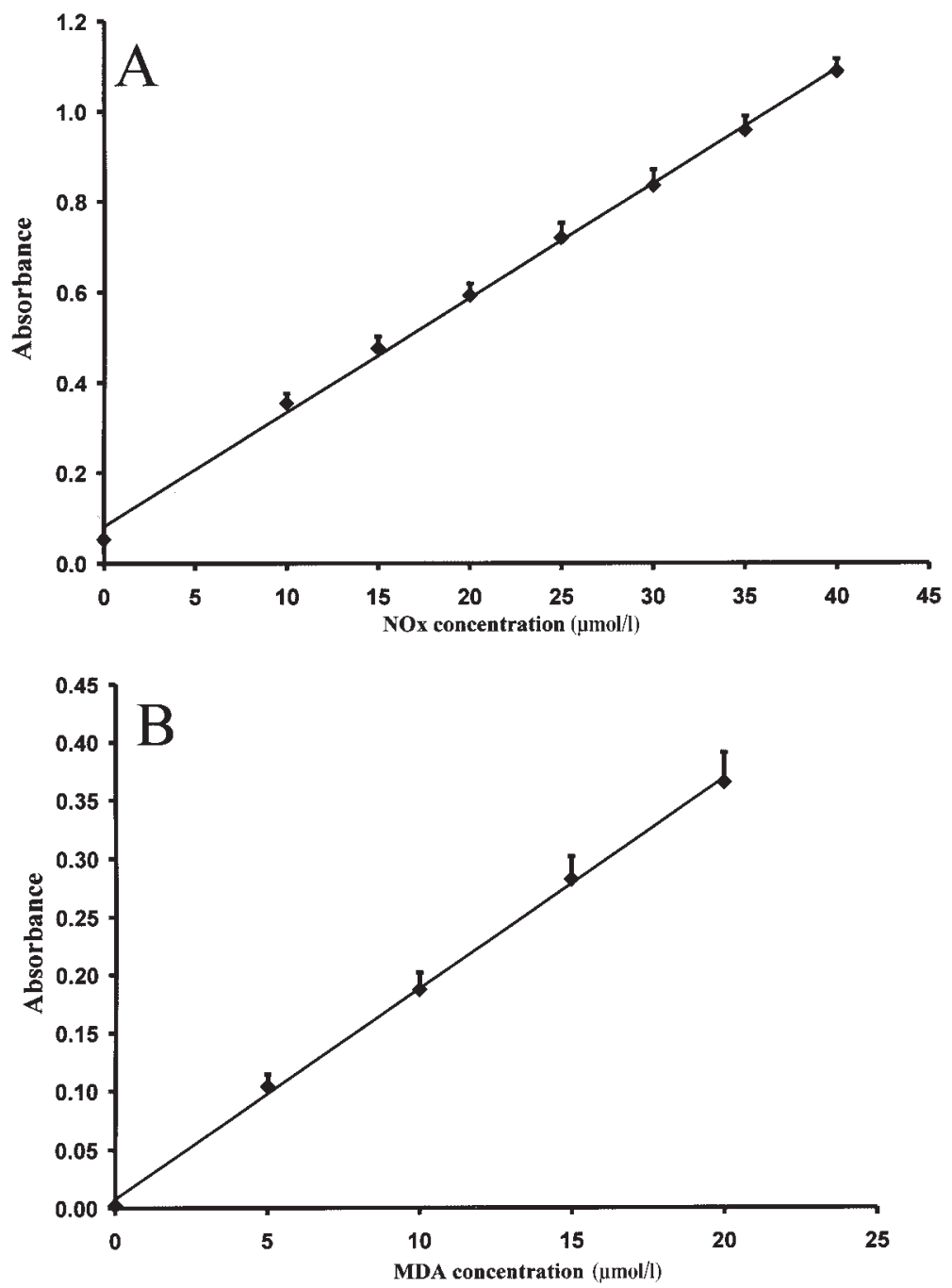

Figure 1 Standard curve (A) for the measurement of nitrate plus nitrite $(n=14 ; r=0.999, p<0.001)$ at $540 \mathrm{~nm}$ and $(B)$ for the

measurement of malondialdehyde $(n=10 ; r=0.999, p<0.001)$ at $586 \mathrm{~nm}$. 
Table 3 The measurement of nitrate and nitrite. Analytical recovery including the ultrafiltration step.

\begin{tabular}{lllll}
\hline \multicolumn{2}{l}{ NOx concentration $(\mu \mathrm{mol} / \mathrm{l})$} & \multirow{2}{*}{ Recovery (\%) } \\
\cline { 1 - 2 } Initial & Added & Expected & Measured \\
\hline 11 & 10 & 21 & 18.8 & 89.9 \\
9.6 & 8.75 & 18.35 & 17.6 & 95.9 \\
8.4 & 7.5 & 15.9 & 15.2 & 95.5 \\
6.8 & 6.2 & 13 & 13.4 & 102.4 \\
5.5 & 5 & 10.5 & 11.8 & 105.7 \\
2.7 & 2.5 & 5.2 & 5.7 & 108.8 \\
\hline
\end{tabular}

Known NOx concentrations were added to plasma before ultrafiltration and then diluted and assayed.
Table 4 The measurement of malondialdehyde. Analytical recovery.

\begin{tabular}{lllll}
\hline \multicolumn{3}{l}{ MDA concentration $(\mu \mathrm{mol} / \mathrm{l})$} & \multirow{2}{*}{ Recovery (\%) } \\
\cline { 1 - 2 } Initial & Added & Expected & Measured & \\
\hline 0.135 & 0 & 0.135 & 0.13 & 96.5 \\
0.135 & 0.5 & 0.635 & 0.54 & 85 \\
0.135 & 1 & 1.135 & 0.99 & 87.2 \\
0.135 & 1.5 & 1.635 & 1.54 & 94.1 \\
0.135 & 2 & 2.135 & 1.97 & 92.2 \\
\hline
\end{tabular}

Known MDA concentrations were added to a sample with fixed known concentration.

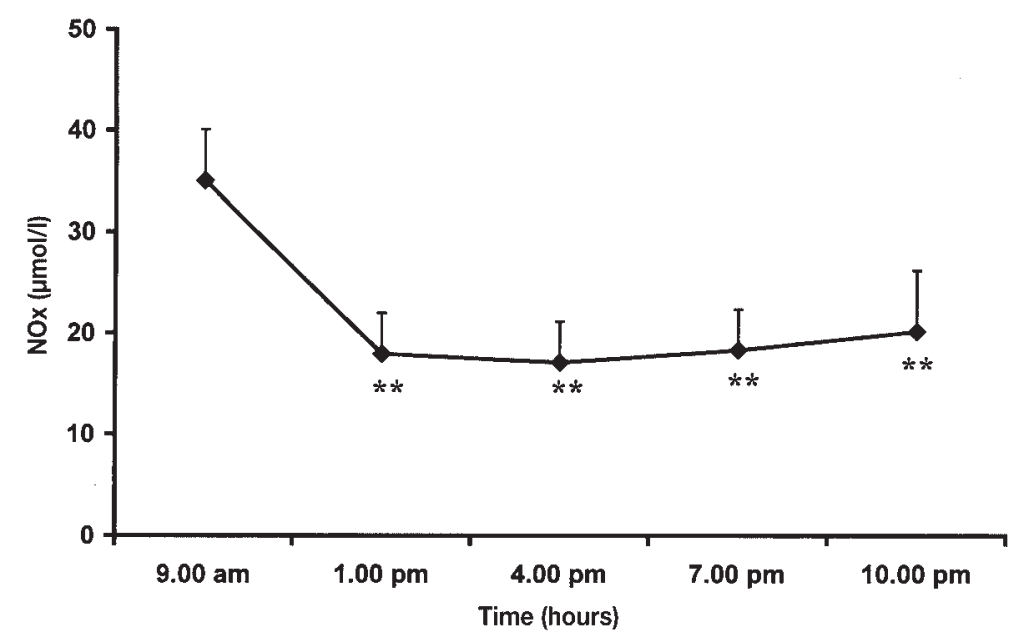

Figure 2 Plasma levels of NOx in five subjects at different times of the day. ${ }^{*} p<0.001$ vs. 10 am.

$4 \mathrm{pm}, 7 \mathrm{pm}, 10 \mathrm{pm})$, were assayed; the results are reported in Figure 2. These data indicate that NOx levels significantly declined from 9 am to $1 \mathrm{pm}$, without further changes during the rest of the day.

Mean plasma NOx levels were significantly higher in athletes $(48.5 \pm 13.2 \mu \mathrm{mol} / \mathrm{l})$ compared to both control subjects $(38.2 \pm 11.5 \mu \mathrm{mol} / \mathrm{l}, \mathrm{p}<0.05)$ and to smokers $(28.2 \pm 9.4 \mu \mathrm{mol} / \mathrm{l}, \mathrm{p}<0.001)$. Furthermore, the mean value observed in healthy subjects was significantly $(p<0.05)$ different from that observed in smokers (Figure 3, panel A).

\section{MDA assay}

\section{Analytical performance}

The limit of quantification, defined as the concentration corresponding to the mean value of 10 determinations of the zero calibrator $+2 \mathrm{SD}$, was $0.03 \mu \mathrm{mol} / \mathrm{l}$. The assay was found to be linear from 0.03 to $20 \mu \mathrm{mol} / \mathrm{l}$ ( $\mathrm{r}=0.99$, $\mathrm{p}<0.001$; Figure 1, panel B). Both within-run and between-run assay imprecision, tested by repeatedly assaying six plasma samples with different MDA concentrations (from 1.81 to $3.19 \mu \mathrm{mol} / \mathrm{l}$ ), were always below $5 \%$. The dilution of plasma samples (to $1: 20$ ) did not significantly modify the estimation of plasma MDA levels. In order to evaluate the recovery, known amounts of MDA were added to five different aliquots of the
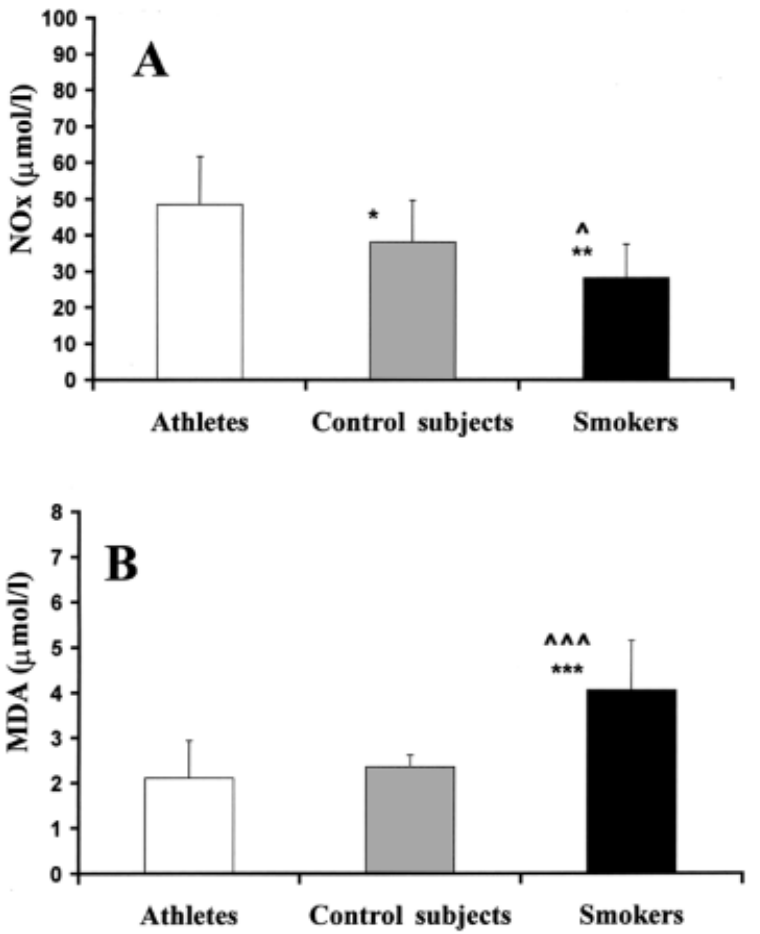

Figure 3 Plasma levels of (A) NOx and (B) MDA in athletes, sedentary healthy subjects and smokers. The values are expressed as mean \pm SD. ${ }^{*} p<0.05,{ }^{* *} p<0.001,{ }^{* *} p<0.001 \mathrm{vs}$. athletes; ${ }^{\wedge} p<0.05,{ }^{\wedge \wedge} \wedge<0.001$ vs. control subjects. 

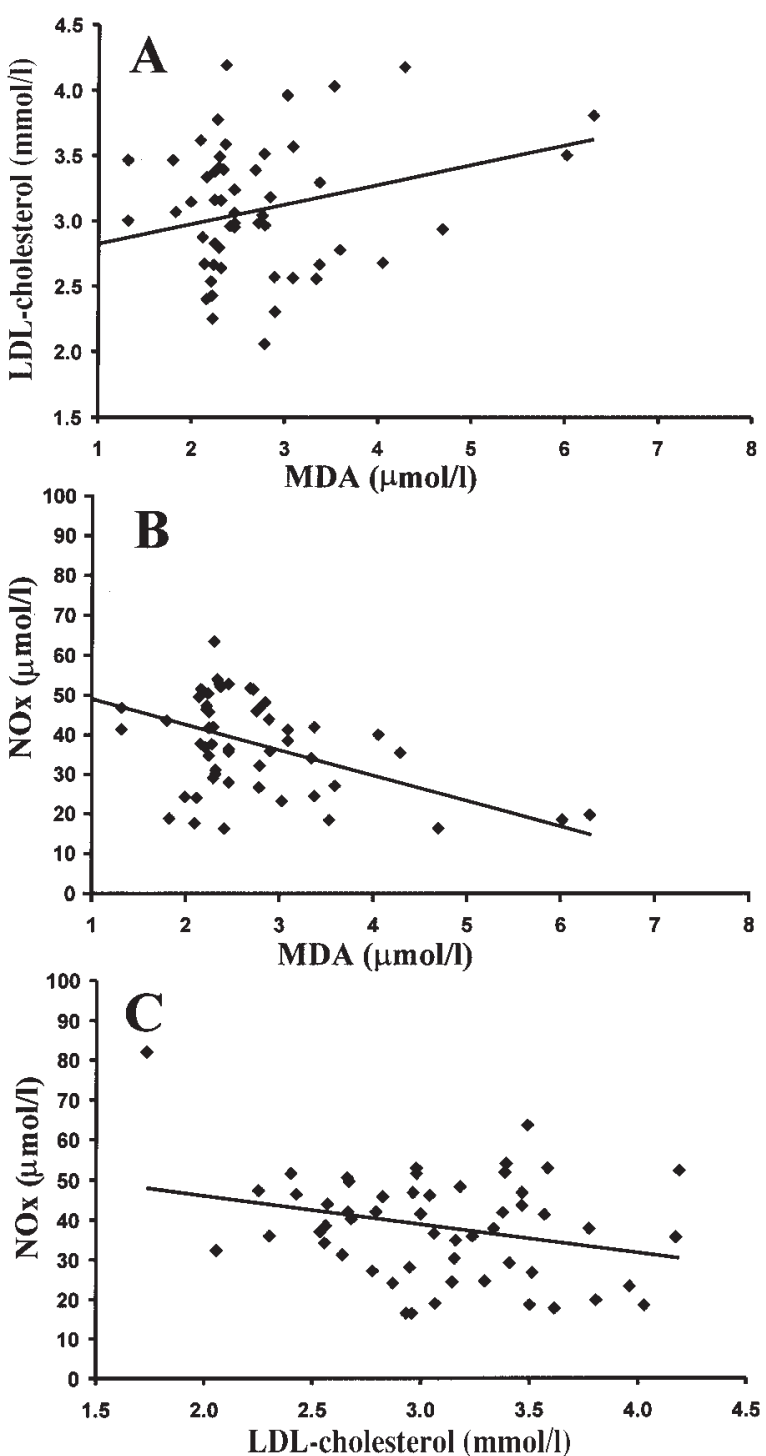

Figure 4 The relationship between (A) plasma MDA and LDL-cholesterol $(r=0.3, p<0.05)$, (B) plasma levels of MDA and NOx $(r=-0.5, p<0.001)$ and (C) plasma LDL-cholesterol and $\mathrm{NOx}(r=-0.3, p<0.001)$ in the entire study population.

same plasma sample. The results obtained are reported in Table 4; an analytical recovery of $91.0 \pm 4.8 \%$ was observed.

\section{Clinical results}

Mean plasma MDA concentration was significantly higher in smokers $(4.1 \pm 1.1 \mu \mathrm{mol} / \mathrm{l})$ compared to control subjects $(2.4 \pm 0.26 \mu \mathrm{mol} / \mathrm{l}, \mathrm{p}<0.001)$, as well as to athletes $(2.1 \pm 0.8 \mu \mathrm{mol} / \mathrm{l}, \mathrm{p}<0.001)$ (Figure 3, panel B).

\section{Relationship between NOx, MDA and LDL-cholesterol in the entire studied population}

A direct linear relationship was found between the circulating levels of MDA and LDL-cholesterol in the entire studied population $(r=0.3, p<0.05$; Figure 4, panel A). Furthermore, a significant inverse linear relationship was observed when comparing plasma NOx concentrations with plasma concentrations of MDA $(r=-0.49, p<0.001)$ or LDL-cholesterol $(r=-0.3, p<0.001)$ in the entire study population (Figure 4, panels $B$ and C).

\section{Discussion}

Since the half-life of NO in vivo is very short, a direct quantitative estimation of its basal production is very difficult. In addition, different methodological approaches available retain different characteristics due to measurement of NO itself or its final metabolites, instantaneously or cumulatively. Chemiluminescence represents a sensitive and accurate method, although it requires careful sample preparation to reduce the loss of NO (9). Electron paramagnetic resonance is not particularly sensitive and is not widely used to quantify NO (9). In addition, these techniques require expensive, specialized equipment and considerable expertise to perform the assay; consequently, they are not appropriate for the clinical routine. NO-sensitive electrodes, recently manufactured, can be inserted directly into the sample and permit to monitor NO synthesis in real time, and progressing reactions over time (10). Because of their differential nature, electrochemical measurements do not permit the evaluation of basal NO production. In addition, these sensors, often modified to suit individual applications, are still being validated.

Spectrophotometric assays available for the indirect assessment of NO production are based on very different principles: the Griess reaction, which quantifies NOx after its reduction, and the hemoglobin method, which provides an estimation of oxyhemoglobin to methemoglobin due to NO (9). Hemoglobin method provides a highly sensitive method that does not require specialized apparatus to measure $\mathrm{NO}$ release in cell or tissue preparations or in perfusion experiments, and is particularly suitable for kinetic studies. However, its specificity is relative, because peroxynitrite, in addition to NO, can cause absorbance changes (11). In addition, care must be taken with regard to time, $\mathrm{pH}$ and temperature, because even small variations in these parameters can greatly influence the final result.

Since inorganic nitrites and nitrates are stable endmetabolites of NO, the assessment of plasma NOx concentration has become the main procedure in which clinical studies can attempt to assess changes in NO production in vivo (12-14). This method is the only one available in which the presence of oxygen or superoxide anion in the sample, as well as NO instability, is not a problem.

Our data indicate that the spectrophotometric methods for NOx assay are simple, cheap and reproducible. Furthermore, our results on normal subjects and athletes are similar to those previously reported (15). It is important to emphasize that several analytical, physiological, and clinical factors should be taken into account in order to set up an assay method for NOx and evaluate its results. Indeed, some differences may be found when comparing NOx plasma levels from different studies, even when only samples from healthy subjects 
(reference values) are considered (15-17). Confounding factors which may explain these discrepancies are: differences in gender, diet, physical activity, smoking, as well as the time of blood sampling (18-21). In addition, the contribution of the endothelial NO synthase gene may be partly responsible for the differences $(22$, 23).

Since all subjects enrolled in the present study fasted and followed a low-nitrate diet, potential differences in dietary composition or nitrate intake should not account for NOx variation. Since the time of blood sampling can affect plasma NOx concentration, as suggested by the significant variation in plasma NOx concentration throughout the day (Figure 2), we decided to collect blood only from subjects at rest and at the same time of day ( $9.00 \mathrm{am})$. Finally, our data were obtained from females during the early follicular phase of the menstrual cycle, when blood levels of estrogens are still relatively low and their possible effects on endothelial function are minimized.

The direct measurement of free radical generation using electron spin resonance represents an accurate method applicable to experimental models, but it is not suitable for use in humans (24). Ex vivo spin trapping has been utilized in clinical settings but its use is limited by the ex vivo generation of secondary oxidative species (25). Isoprostanes, derived from arachidonic acid, have been recently indicated as markers of antioxidant deficiency and oxidative stress (26) but are still questioned for their specificity and accuracy. In addition, other mechanisms leading to molecular changes in plasma proteins may help to evaluate the excess free radical generation. Reactive nitrogen species can react with tyrosine residues of proteins; thus, protein nitration may represent a marker for nitrating molecules and it can be used as a marker of oxidative protein damage (27).

However, the methods employed to evaluate these molecules are often elaborate and this limits their application in routine clinical diagnosis. Indeed, the measurements of 8-isoprostane in plasma by immunoenzymatic method require sample purification that takes hours (28). Nitrotyrosine levels are determined in previously filtered plasma samples by HPLC (29), or by Western blot and ELISA methods (30).

MDA, generated by the decomposition of polyunsaturated fatty acid peroxides, is largely used as an index of oxidative stress in cells and tissues (6), and MDA levels correlate closely with those of isoprostane (31).

At present, several commercial kits are available that offer a straightforward and rapid procedure for evaluating MDA in plasma, requiring equipment commonly found in biochemical laboratories. However, it is still a matter of debate whether the assay of this molecule represents a reliable method for the determination of free radical generation suitable for clinical studies (32). Analytical aspects and the assay performance could explain some of the discrepancies reported using different methods to estimate free radical generation (32). In particular, the measurement of MDA can be greatly affected by blood collection and storage procedures.
Indeed, unless assayed immediately, samples must be kept on ice after collection and centrifuged at $4{ }^{\circ} \mathrm{C}$. Furthermore, BHT must also be added to samples to a final concentration of $5 \mathrm{mmol} / \mathrm{l}$; if no antioxidant is added, new lipid peroxidation can occur and bias will result. Unless assayed immediately, samples should be frozen at $-80^{\circ} \mathrm{C}$ to prevent both loss of MDA and new sample oxidation. After the incubation at $45^{\circ} \mathrm{C}$, turbid samples may not clear upon centrifugation. In this case, a dilution of the sample to obtain clear samples is possible without any loss of accuracy (one can dilute 200-50 $\mu \mathrm{l}$ in $1000 \mu \mathrm{l}$ of total reaction mixture). Finally, the used sample should not be re-frozen.

\section{Exercise, smoking habit, nitric oxide and oxidative stress}

Our findings show that aerobic physical training and plasma NO availability are positively associated and thus are in accordance with other recent results (20, 33). Enhanced blood flow due to exercise increases laminar shear stress. It is well-known that shear stress upregulates the expression and activity of endothelial nitric oxide synthase (eNOS) in the endothelial cells $(34,35)$.

Another possible mechanism by which exercise could improve NO availability might be related to the prevention of oxidative stress. In fact, if at high NO concentrations, resulting from the activation of inducible NOS, and in the presence of oxidant molecules with which it can react, NO promotes nitration or oxidative reactions; at physiological levels NO protects endothelium against oxidant species including oxLDL (36). Accordingly, recent data indicate that physical activity can improve endothelial-dependent vasodilation and prevent the age-related NO breakdown in elderly subjects, by a mechanism essentially related to its antioxidant activity (37).

In addition, the effects of NO on antioxidant molecules, such as glutathione (GSH), and on enzymes related to its metabolism, are now recognized to be important. GSH protects the endothelium by acting as a physiological free radical scavenger. Recent data indicate that NO, at a physiological level of endothelial production, induces the synthesis of GSH through a mechanism involving $\gamma$-glutamylcysteine synthase and $\gamma$-glutamyl transpeptidase (36). In addition, chronic N(omega)-nitro-L-arginine methyl ester L-NAME (NOS inhibitor) treatment in rats has proved to increase MDA levels and cause depletion of NO, NOS activity, NOS protein expression and to decrease $\mathrm{GSH} /$ GSSG (GSSG, oxidized glutathione) ratio (38). Chronic training reduced MDA and improved both NO and antioxidant molecules, while the combination of physical exercise and L-NAME induces normalization of antioxidant enzyme activity as well as protein expression (38). Thus, the existence of this cooperative interaction between $\mathrm{NO}$ and GSH may be crucial for the protection of endothelium against oxidative stress. Further studies are required in this field.

Cigarette smoke (especially the gas phase) contains 
high amounts of free radicals and pro-oxidants (39). MDA levels, measured in erythrocytes and evaluated as indicators of oxidant status, were significantly higher in smokers compared to non-smokers (40). Thus, smokers appear to be particularly susceptible to the activity of oxygen-derived free radicals, and plasma levels of 8isoprostane in smokers are increased (41). A blunted response to endothelium-dependent vasodilators has been revealed in chronic smokers, which improves with antioxidant treatment (42). In addition, the vasoconstrictor response to the inhibition of $\mathrm{NO}$ by $\mathrm{NG}^{\mathrm{G}}$-monomethyl-L-arginine (L-NMMA) is reduced in long-term smokers, suggesting impaired basal NO-mediated vasodilation (43).

In line with these results, our data show a marked reduction in the plasma levels of NOx in smokers compared to control subjects. Furthermore, low levels of plasma NOx are associated with significantly higher levels of plasma MDA in heavy smokers. Finally, a significant inverse relationship between NOx and MDA or plasma LDL-cholesterol plasma levels was found in the combined groups of studied subjects. These data suggest that although the mechanism of smoking-related endothelial dysfunction is certainly multifactorial, this effect may be partly explained by the sequence of events including impaired NO production or enhanced NO degradation resulting from oxygen-derived free radical production which would then lead to enhanced lipid peroxidation and MDA production $(38,40)$.

Thus, if decreased NO bioavailability in smokers supports the existence of a link between NO activity and oxidative stress, regular physical activity appears to represent a physiologic antioxidant.

\section{Conclusions}

The evaluation of nitrite plus nitrate and MDA in plasma samples represents sensitive, specific and practicable indicators of NO availability and oxidative stress, respectively. Both methods are quick and simple and can be used to process a large number of samples. For this reason, these methods may be considered suitable for routine application in clinical chemistry laboratories and for use in physiopathological studies involving human blood samples. However, particular care must be taken with collection and storage of plasma samples.

\section{References}

1. Darley-Usmar V, Halliwell B. Blood radicals: reactive nitrogen species, reactive oxygen species, transition metal ions, and the vascular system. Pharm Res 1996; 13:649-62.

2. Hogg N, Kalyanaraman B. Nitric oxide and lipid peroxidation. Biochim Biophys Acta 1999; 1411:378-84.

3. Archer $S$. Measurement of nitric oxide in biological models. FASEB J 1993; 7:349-60.

4. Jackson MJ. An overview of methods for assessment of free radical activity in biology. Proc Nutr Soc 1999; 58: 1001-6.
5. Esterbauer H, Cheeseman KH. Determination of aldheydic lipidic peroxidation product: malonaldehyde and 4-hydroxynonenal. Meth Enzymol 1990; 186:407-21.

6. Janero DR. Malondialdehyde and thiobarbituric acid-reactivity as diagnostic indices of lipid peroxidation and peroxidative tissue injury. Free Radic Biol Med 1990; 9:515-40.

7. Buchfuhrer MJ, Hansen JE, Robinson TE, Sue DY, Wasserman K, Whipp BJ. Optimizing the exercise protocol for cardiopulmonary assessment. J Appl Physiol 1983; 55:155864.

8. Green LC, Wagner DA, Glogowski J, Skipper PL, Wishnok JS, Tannenbaum ST. Analysis of nitrate, nitrite and $\left({ }^{15} \mathrm{~N}\right) \mathrm{ni}-$ trate in biological fluids. Analyt Biochem 1982; 126:131-8.

9. Archer $S$. Measurement of nitric oxide in biological models. FASEB J 1993; 7:349-60.

10. Kiechle FL, Malinski T. Nitric oxide. Biochemistry, pathophysiology, and detection. Am J Clin Pathol 1993; 100: 567-75.

11. Schmidt K, Klatt P, Mayer B. Reaction of peroxynitrite with oxyhaemoglobin: interference with photometrical determination of nitric oxide. Biochem J 1994; 301:645-7.

12. Matata BM, Galinanes M. Effect of diabetes on nitric oxide metabolism during cardiac surgery. Diabetes 2001; 50: 2603-10.

13. Yu CM, Fung PC, Chan G, Lai KW, Wang Q, Lau CP. Plasma nitric oxide level in heart failure secondary to left ventricular diastolic dysfunction. Am J Cardiol 2001; 88:867-70.

14. Sanada M, Higashi Y, Nakagawa K, Sasaki S, Kodama I, Sakashita $\mathrm{T}$, et al. Estrogen replacement therapy in postmenopausal women augments reactive hyperemia in the forearm by reducing angiotensin converting enzyme activity. Atherosclerosis 2001; 158:391-7.

15. Jungersten L, Ambring A, Wall B, Wennmalm A. Both physical fitness and acute exercise regulate nitric oxide formation in healthy humans. J Appl Physiol 1997; 82: $760-4$.

16. Node K, Kitakaze M, Yoshikawa H, Kosaka H, Hori M. Reduced plasma concentrations of nitrogen oxide in individuals with essential hypertension. Hypertension 1997; 30:405-8.

17. Kawano H, Motoyama T, Kugiyama K, Hirashima O, Ohgushi $\mathrm{M}$, Fujii $\mathrm{H}$, et al. Gender difference in improvement of endothelium-dependent vasodilation after estrogen supplementation. J Am Coll Cardiol 1997; 30:914-9.

18. Jilma B, Kastner J, Mensik C, Vondrovec B, Hildebrandt J, Krejcy $\mathrm{K}$, et al. Sex differences in concentrations of exhaled nitric oxide and plasma nitrate. Life Sci 1996; 58:469-76.

19. Rhodes P, Leone AM, Francis PL, Struthers AD, Moncada S. The L-arginine: nitric oxide pathway is the major source of plasma nitrite in fasted humans. Biochem Biophys Res Commun 1995; 209:590-6.

20. Cuzzolin L, Lussignoli S, Crivellente F, Adami A, Schena F, Bellavite $P$, et al. Influence of an acute exercise on neutrophil and platelet adhesion, nitric oxide plasma metabolites in inactive and active subjects. Int J Sports Med 2000; 21:289-93.

21. Node K, Kitakaze M, Yoshikawa H, Kosaka H, Hori M. Reversible reduction in plasma concentration of nitric oxide induced by cigarette smoking in young adults. Am J Cardiol 1997; 79:1538-41.

22. Wang XL, Mahaney MC, Sim AS, Wang J, Wang J, Blangero J, et al. Genetic contribution of the endothelial constitutive nitric oxide synthase gene to plasma nitric oxide levels. Arterioscler Thromb Vasc Biol 1997; 17:3147-53.

23. Tsukada T, Yokoyama K, Arai T, Takemoto F, Hara S, Yamada $A$, et al. Evidence of association of the ecNOS gene 
polymorphism with plasma NO metabolite levels in humans. Biochem Biophys Res Commun 1998; 245:190-3.

24. Garlick PB, Davies MJ, Hearse DJ, Slater TF. Direct detection of free radicals in the reperfused rat heart using electron spin resonance spectroscopy. Circ Res 1987; 61:757-60.

25. Grech ED, Dodd NJ, Bellamy CM, Perry RA, Morrison WL, Ramsdale DR. Free-radical generation during angioplasty reperfusion for acute myocardial infarction. Lancet 1993; 341:990-1.

26. Pratico D, Lawson JA, Rokach J, Fitzgerald GA. The isoprostanes in biology and medicine. Trends Endocrinol Metab 2001; 12:243-7.

27. Halliwell B. What nitrates tyrosine? Is nitrotyrosine specific as a biomarker of peroxynitrite formation in vivo? FEBS Lett 1997; 411:157-60.

28. Lubrano V, Vassalle C, L'Abbate A, Zucchelli GC. A new method to evaluate oxidative stress in humans. Immunoanalyse Biol specialisee 2002; 17:172-5.

29. Kamisaki Y, Wada K, Nakamoto K, Kishimoto Y, Kitano M, Itoh $\mathrm{T}$. Sensitive determination of nitrotyrosine in human plasma by isocratic high-performance liquid chromatography. J Chromatogr B Biomed Appl 1996; 685:343-7.

30. Khan J, Brennand DM, Bradley N, Gao B, Bruckdorfer R, Jacobs $\mathrm{M}$, et al. 3-Nitrotyrosine in the proteins of human plasma determined by an ELISA method. Biochem J 1998; 330:795-801.

31. Walsh SW, Vaughan JE, Wang Y, Roberts LJ 2nd. Placental isoprostane is significantly increased in preeclampsia. FASEB J 2000; 14:1289-96.

32. Moore K, Roberts LJ 2nd. Measurement of lipid peroxidation. Free Radic Res 1998; 28:659-71.

33. Bonsignore MR, Morici G, Riccobono L, Insalaco G, Bonanno $A$, Profita $M$, et al. Airway inflammation in nonasthmatic amateur runners. Am J Physiol Lung Cell Mol Physiol 2001; 281:L668-76.

34. Noris M, Morigi M, Donadelli R, Aiello S, Foppolo M, Todeschini $\mathrm{M}$, et al. Nitric oxide synthesis by cultured endothelial cells is modulated by flow conditions. Circ Res 1995; 76:536-43.

35. Niebauer J, Cooke JP. Cardiovascular effects of exercise: role of endothelial shear stress. J Am Coll Cardiol 1996; 28:1652-60.

36. Moellering D, Mc Andrew J, Patel RP, Forman HJ, Mulcahy $\mathrm{RT}$, Jo H, et al. The induction of GSH synthesis by nanomolar concentrations of $\mathrm{NO}$ in endothelial cells: a role for gamma-glutamylcysteine synthetase and gamma-glutamyl transpeptidase. FEBS Lett 1999; 448:292-6.

37. Taddei S, Galetta F, Virdis A, Ghiadoni L, Salvetti G, Franzoni $F$, et al. Physical activity prevents age-related impairment in nitric oxide availability in elderly athletes. Circulation 2000; 25:2896-01.

38. Husain K, Hazelrigg SR. Oxidative injury due to chronic nitric oxide synthase inhibition in rat: effect of regular exercise on the heart. Biochim Biophys Acta 2002; 1587:75-82.

39. Church DF, Pryor WA. Free-radical chemistry of cigarette smoke and its toxicological implications. Environ Health Perspect 1985; 64:111-26.

40. Durak I, Elgun S, Kemal Bingol N, Burak Cimen MY, Kacmaz M, Buyukkocak S, et al. Effects of cigarette smoking with different tar content on erythrocyte oxidant/antioxidant status. Addict Biol 2002; 7:255-8.

41. Morrow JD, Frei B, Longmire AW, Gaziano JM, Lynch SM, Shyr $Y$, et al. Increase in circulating products of lipid peroxidation (F2-isoprostanes) in smokers. Smoking as a cause of oxidative damage. N Engl J Med 1995; 332: 1198-203.

42. Heitzer T, Just $\mathrm{H}$, Munzel T. Antioxidant vitamin $\mathrm{C}$ improves endothelial dysfunction in chronic smokers. Circulation 1996; 94:6-9.

43. McVeigh GE, Lemay L, Morgan D, Cohn JN. Effects of longterm cigarette smoking on endothelium-dependent responses in humans. Am J Cardiol 1996; 78:668-72.

Received 14 December 2001, revised 11 June 2002, accepted 20 June 2002

Corresponding author: Dott. Cristina Vassalle, Istituto di Fisiologia, Clinica-Area di ricerca CNR, Via Moruzzi 1, 56100 Pisa, Italy

Phone: +39-050-3152363, Fax:+39-050-3152166

E-mail: cristina.vassalle@nsifc.ifc.pi.cnr.it 